\title{
Microwave assisted catalytic reduction of sulfur dioxide with methane over $\mathrm{MoS}_{2}$ catalysts
}

\author{
Xunli Zhang ${ }^{1}$, David O. Hayward, Colleen Lee, D. Michael P. Mingos* \\ Department of Chemistry, Imperial College of Science, Technology and Medicine, South Kensington, London SW7 2AY, UK
}

Received 25 November 2000; received in revised form 6 January 2001; accepted 18 March 2001

\begin{abstract}
The catalytic reduction of sulfur dioxide with methane to form carbon dioxide and sulfur has been studied over $\mathrm{MoS}_{2} / \mathrm{Al}_{2} \mathrm{O}_{3}$ catalysts. The reaction has been found to occur with microwave $(2.45 \mathrm{GHz})$ heating at recorded temperatures as much as $200^{\circ} \mathrm{C}$ lower than those required when conventional heating was used. An activation energy of $117 \mathrm{~kJ} \mathrm{~mol}^{-1}$ has been calculated for the conventionally heated reaction, but an Arrhenius analysis of the data obtained with microwave heating was not possible, probably because of temperature variations in the catalyst bed. The existence of hot spots in the catalysts heated by microwave radiation has been verified by the detection of $\alpha$-alumina at a recorded temperature some $200^{\circ} \mathrm{C}$ lower than the temperature at which the $\gamma$ - to $\alpha$-alumina phase transition is normally observed. Among four catalysts prepared in different ways, a mechanically mixed catalyst showed the highest conversion of $\mathrm{SO}_{2}$ and $\mathrm{CH}_{4}$ for microwave heating at a given temperature. Supported catalysts, sulfided either by conventional heating or under microwave conditions, showed little difference in the extent of $\mathrm{SO}_{2}$ and $\mathrm{CH}_{4}$ conversions. The highest conversions to carbon dioxide and sulfur, combined with low production of undesirable side products, was obtained when the molar ratio of $\mathrm{SO}_{2}$ to $\mathrm{CH}_{4}$ was equal to two, the stoichiometric ratio. (c) 2001 Elsevier Science B.V. All rights reserved.
\end{abstract}

Keywords: Sulfur dioxide; Methane; Catalytic reduction; Microwave irradiation; $\mathrm{MoS}_{2}$ catalyst

\section{Introduction}

Sulfur dioxide is generally accepted to be the most important precursor to acid rain. It is produced in vast quantities by large fuel-consuming installations such as non-ferrous smelters and the need to find efficient and economical methods of reducing the amount of sulfur dioxide emissions has become ever more urgent, as evidence demonstrating the detrimental effects of

\footnotetext{
* Corresponding author. Present address: St. Edmund Hall, University of Oxford, Oxford OX1 4AR, UK. Fax: +44-1865-279030. E-mail address: michael.mingos@seh.ox.ac.uk (D.M.P. Mingos).

${ }^{1}$ Present address: Department of Chemistry, University of Hull, Hull HU6 7RX, UK.
}

both sulfur dioxide and acid rain on the environment has accumulated [1,2].

A number of processes for the removal of sulfur dioxide have been developed and evaluated [3-6], and they can be classified into three groups.

1. Conversion of sulfur dioxide into solid salts such as calcium sulfate and calcium sulfide by the following reactions.

$$
\begin{aligned}
& \mathrm{CaO}(\mathrm{s})+\mathrm{SO}_{2}(\mathrm{~g})+\frac{1}{2} \mathrm{O}_{2}=\mathrm{CaSO}_{4}(\mathrm{~s}) \\
& 4 \mathrm{CaO}(\mathrm{s})+4 \mathrm{SO}_{2}(\mathrm{~g})=3 \mathrm{CaSO}_{4}(\mathrm{~s})+\mathrm{CaS}(\mathrm{s})
\end{aligned}
$$

2. Oxidation of sulfur dioxide to sulfur trioxide, which may then be converted into sulfuric acid. 


$$
\begin{aligned}
& \mathrm{SO}_{2}(\mathrm{~g})+\frac{1}{2} \mathrm{O}_{2}(\mathrm{~g})=\mathrm{SO}_{3}(\mathrm{~g}) \\
& \mathrm{SO}_{3}(\mathrm{~g})+\mathrm{H}_{2} \mathrm{O}(\mathrm{l})=\mathrm{H}_{2} \mathrm{SO}_{4}(\mathrm{l})
\end{aligned}
$$

3. Reduction of sulfur dioxide to elemental sulfur with a number of reducing agents such as hydrogen, hydrogen sulfide, carbon, carbon monoxide and hydrocarbons.

$$
\mathrm{SO}_{2}(\mathrm{~g})+\text { reductants } \rightarrow[\mathrm{S}](\mathrm{s})
$$

In method (1), large amounts of essentially worthless materials are produced, which require disposal and subsequently result in other environmental problems. Sulfuric acid produced in method (2) is a product which is difficult to store and transport. As an end product, elemental sulfur has several advantages over sulfuric acid, because it can be handled, stored and transported safely, with no danger to the environment. Therefore, method (3), which involves reducing sulfur dioxide to elemental sulfur, especially with methane as the reductant, appears the most promising and has attracted increasing attention from researchers in recent years because of the relative availability and low price of methane.

The principal reaction for the reduction of $\mathrm{SO}_{2}$ by $\mathrm{CH}_{4}$ can be represented as

$$
2 \mathrm{SO}_{2}(\mathrm{~g})+\mathrm{CH}_{4}(\mathrm{~g})=2[\mathrm{~S}](\mathrm{g})+\mathrm{CO}_{2}(\mathrm{~g})+2 \mathrm{H}_{2} \mathrm{O}(\mathrm{g})
$$

where $[\mathrm{S}]$ denotes the various sulfur species $\left(\mathrm{S}_{1}\right.$, $\mathrm{S}_{2}, \ldots \mathrm{S}_{8}$ ) in the gas phase. From thermodynamic data it can be calculated that most of the sulfur will exist as diatomic molecules at temperatures $>600^{\circ} \mathrm{C}$ [7].

Sarlis and Berk [8] have shown that the homogeneous reaction occurs at a satisfactory rate at temperatures between 650 and $700^{\circ} \mathrm{C}$, but there is significant formation of unwanted by-products such as $\mathrm{H}_{2} \mathrm{~S}$, $\mathrm{COS}, \mathrm{CO}$ and $\mathrm{H}_{2}$. To achieve both a high conversion of sulfur dioxide and a high product selectivity it is necessary to work with heterogeneous catalytic systems, which operate in a lower temperature range. Much research has been conducted in this area, the catalysts used being activated alumina [8] and metal sulfides such as $\mathrm{MoS}_{2}$ and $\mathrm{CoS}_{2}$ [9-12].

Recent studies [13-15] have shown that the rates of many heterogeneous catalytic reactions can be considerably enhanced by using microwave radiation to heat the catalyst. This effect is thought to arise because the reaction sites are at a considerably higher temperature than the bulk of the catalyst. This paper reports an investigation into the effect of microwave heating on the catalytic reduction of $\mathrm{SO}_{2}$ with $\mathrm{CH}_{4}$ over $\mathrm{MoS}_{2}$ catalysts, which were prepared in a variety of ways.

\section{Experimental}

\subsection{Materials}

The following chemicals were purchased from Aldrich Chemicals: sulfur dioxide $\mathrm{SO}_{2}$, purity $>99.9 \%$; methane $\mathrm{CH}_{4}$, purity >99.0\%; molybdenum disulfide $\mathrm{MoS}_{2}$, purity $>99 \%$.

Aluminum oxide (activated, 99\% $\mathrm{Al}_{2} \mathrm{O}_{3}$, surface area $90 \mathrm{~m}^{2} \mathrm{~g}^{-1}$ ) and ammonium heptamolybdate $\left(\mathrm{NH}_{4}\right)_{6}\left[\mathrm{Mo}_{7} \mathrm{O}_{24}\right] \cdot 4 \mathrm{H}_{2} \mathrm{O}$ were supplied by Alfa, Johnson Matthey plc.

\subsection{Catalyst preparation}

The catalysts used in this study were prepared either by mechanical mixing or by impregnation.

\subsubsection{Mechanically mixed catalysts (MC)}

$\mathrm{MoS}_{2}$ was purchased as a powder (particle diameter $2 \mu \mathrm{m}$ ) and activated alumina as $3.2 \mu \mathrm{m}$ pellets. The activated alumina was ground and sieved to give the desired size before use. The $\mathrm{MoS}_{2}$ powder was compressed into pellets in a stainless steel die before also being ground and sieved to the desired size.

Catalyst MC-1 was made by mixing $30 \mathrm{wt} . \% \mathrm{MoS}_{2}$ with $70 \mathrm{wt} . \%$ alumina, both in the same particle size range $(152-178 \mu \mathrm{m})$.

Catalyst MC-2 was made by first mixing $30 \mathrm{wt} . \%$ $\mathrm{MoS}_{2}(2 \mu \mathrm{m})$ with $70 \mathrm{wt} . \%$ alumina $(66 \mu \mathrm{m})$, then compressing the mixture into pellets, followed by grinding and sieving to the desired size $(152-178 \mu \mathrm{m})$.

\subsubsection{Supported catalysts (SC)}

The supported molybdenum catalysts were prepared by impregnating the activated alumina support with ammonium heptamolybdate $\left[\left(\mathrm{NH}_{4}\right)_{6}\left[\mathrm{Mo}_{7} \mathrm{O}_{24}\right] \cdot 4 \mathrm{H}_{2} \mathrm{O}\right]$ solution. An appropriate amount of solution, calculated to produce $30 \mathrm{wt} . \% \mathrm{MoS}_{2}$ on the support, was 
first mixed with alumina and allowed to stand at room temperature for a period of $6 \mathrm{~h}$. The paste was then dried in a furnace with gradual increase of temperature to $105^{\circ} \mathrm{C}$ over a period of $3 \mathrm{~h}$, followed by isothermal heating at $105^{\circ} \mathrm{C}$ for $18 \mathrm{~h}$. Once dried, the sample was calcined in a flow of air at $500^{\circ} \mathrm{C}$ for a period of $2 \mathrm{~h}$. The catalyst precursor was then sulfided at a temperature of $400^{\circ} \mathrm{C}$ for $2 \mathrm{~h}$, using either conventional or microwave heating. The sulfiding gas consisted of a mixture of $\mathrm{H}_{2} \mathrm{~S} / \mathrm{H}_{2}\left(15 \mathrm{~mol} \% \mathrm{H}_{2} \mathrm{~S}\right)$, which was flowed over the catalyst at a rate of $90 \mathrm{ml} \mathrm{min}^{-1}$. Catalyst SC-CH was sulfided in the conventional furnace and catalyst SC-MW was sulfided in the microwave cavity.

\subsection{Characterization of catalysts}

The catalysts used in this study were characterized by using a combination of several analytical methods. The surface area was measured, before and after reaction, by the BET method using a Micromeritics ASAP-2000 analyzer. The composition of the catalysts before and after reaction was determined by X-ray powder diffraction using a PW1710 X-ray diffractometer (Phillips Electronic Instruments) with $\mathrm{Cu}$ $\mathrm{K} \alpha$ radiation. The surface structures of the catalysts were investigated by scanning electron microscopy (SEM) using a JEOL (JSM-T 200) scanning microscope.

\subsection{Experimental procedures}

All reactions were carried out in a laboratory-scale, continuous-flow reaction system with a tubular packed-bed quartz reactor (i.d. $10 \mathrm{~mm}$ ) which could be placed either in a cylindrical microwave cavity or in a conventional furnace [14]. A directional coupler was inserted into the microwave guide system so that the amount of microwave power reflected from the cavity could be measured. This was minimized by tuning the cavity with two adjustable stubs.

The temperature of the catalyst was measured with an Accufiber optical fiber thermometer (Model 10, Luxtron), placed at the center of the catalyst bed. This was calibrated against a chromel/alumel thermocouple before the catalytic studies commenced.

The product mixture from the reactor outlet passed through a heated tube to an ice-water trap, where sul- fur and water were condensed out. This trap was emptied after each reaction. Products remaining in the gas phase were analyzed using a quadruple mass spectrometer (QMS-200D, European Spectrometer Systems).

All the catalytic reactions were carried out under atmospheric pressure at temperatures ranging from 500 to $800^{\circ} \mathrm{C}$. The molar ratio of $\mathrm{SO}_{2}$ to $\mathrm{CH}_{4}$ in the feed gas was varied between 1 and 3, keeping the total flow rate constant at $40 \mathrm{ml} \mathrm{min}^{-1}$. The weight of catalyst used in all experiments was $0.50 \mathrm{~g}$.

The reaction products leaving the reactor consisted mainly of $\mathrm{SO}_{2}, \mathrm{CH}_{4}, \mathrm{CO}_{2}$ and $\mathrm{CO}$, although, some traces of $\mathrm{H}_{2} \mathrm{~S}$ and $\mathrm{H}_{2}$ were observed occasionally. The percentage conversion of sulfur dioxide and methane are given in terms of the percentage of sulfur dioxide and methane that have reacted. Thus,

$\% \mathrm{SO}_{2}$ conversion $=100 \times \frac{\left[\left(\mathrm{SO}_{2}\right)_{\text {in }}-\left(\mathrm{SO}_{2}\right)_{\text {out }}\right]}{\left(\mathrm{SO}_{2}\right)_{\text {in }}}$

$\% \mathrm{CH}_{4}$ conversion $=100 \times \frac{\left[\left(\mathrm{CH}_{4}\right)_{\text {in }}-\left(\mathrm{CH}_{4}\right)_{\text {out }}\right]}{\left(\mathrm{CH}_{4}\right)_{\text {in }}}$

The products yields and selectivities are defined as follows:

$$
\begin{aligned}
& \% \mathrm{CO}_{2} \text { yield }=100 \times \frac{\left(\mathrm{CO}_{2}\right)_{\text {out }}}{\left(\mathrm{CH}_{4}\right)_{\text {in }}} \\
& \% \mathrm{CO} \text { yield }=100 \times \frac{(\mathrm{CO})_{\text {out }}}{\left(\mathrm{CH}_{4}\right)_{\text {in }}} \\
& \% \mathrm{H}_{2} \text { S yield }=100 \times \frac{\left(\mathrm{H}_{2} \mathrm{~S}\right)_{\text {out }}}{\left(\mathrm{SO}_{2}\right)_{\text {in }}}
\end{aligned}
$$

\%Sulfur yield $=100$
$\times \frac{\left[\left(\mathrm{SO}_{2}\right)_{\text {in }}-\left(\mathrm{SO}_{2}\right)_{\text {out }}-\left(\mathrm{H}_{2} \mathrm{~S}\right)_{\text {out }}\right]}{\left(\mathrm{SO}_{2}\right)_{\text {in }}}$

$\%$ Sulfur selectivity $=100 \times \frac{\text { sulfur yield }}{\mathrm{SO}_{2} \text { conversion }}$

The effectiveness of the various catalysts were primarily judged by the conversion/yield criteria. 
Table 1

Surface area analysis of the catalyst $\left(\mathrm{m}^{2} \mathrm{~g}^{-1}\right)$

\begin{tabular}{llll}
\hline Catalyst & $\begin{array}{l}\text { Before } \\
\text { reaction }\end{array}$ & $\begin{array}{l}\text { After } \\
\text { reaction }\left(\mathrm{CH}^{\mathrm{a}}\right)\end{array}$ & $\begin{array}{l}\text { After reaction } \\
\left(\mathrm{MW}^{\mathrm{b}}\right)\end{array}$ \\
\hline $\mathrm{MC}-1^{\mathrm{c}}$ & 79.98 & 51.68 & 39.22 \\
$\mathrm{MC}-2$ & 74.08 & 42.90 & 12.35 \\
$\mathrm{SC}-\mathrm{CH}$ & 55.45 & 42.21 & 36.51 \\
$\mathrm{SC}-\mathrm{MW}^{\mathrm{d}}$ & 58.46 & 43.42 & 35.63 \\
$\mathrm{MoS}_{2}$ & 5.01 & - & - \\
$\gamma-\mathrm{Al}_{2} \mathrm{O}_{3}$ & 97.04 & - & - \\
\hline
\end{tabular}

${ }^{\mathrm{a}} \mathrm{CH}$ : conventional heating.

${ }^{\mathrm{b}} \mathrm{MW}$ : microwave heating.

${ }^{\mathrm{c}} \mathrm{MC}$ : mixed (mechanically) catalyst.

${ }^{\mathrm{d}} \mathrm{SC}$ : support catalyst.

\section{Results and discussion}

\subsection{Characterization of the catalysts}

\subsubsection{Surface area measurements}

The surface areas of each of the catalysts, measured before and after reaction, are presented in Table 1. In each case, the reaction was carried out for a period of one and a half hours at a measured temperature of $800^{\circ} \mathrm{C}$. It is apparent that the surface areas of the mechanically mixed catalysts were much smaller after reaction when microwave heating was used than they were after conventional heating. For example, the surface area of catalyst MC-2 was $57 \%$ of the original area after conventional heating, but only $17 \%$ of the original area after microwave heating. This indicated that microwave heating caused a considerable reorganization of the catalyst structure.

The similarities in the areas for the $\mathrm{SC}-\mathrm{CH}$ and SC-MW catalysts, both before and after reaction, show that the use of microwave or conventional heating during the catalyst sulfiding process has little effect on the catalyst structure.

\subsubsection{X-ray diffraction analysis}

The mechanically mixed catalyst MC- 2 and the supported catalyst SC-CH were both analyzed by $\mathrm{X}$-ray diffraction after reaction at a measured temperature of $800^{\circ} \mathrm{C}$ using both conventional and microwave heating. Three crystal structures were identified from X-ray data [16]: the $\mathrm{MoS}_{2}$ layer structure (with principal peaks at $2 \theta=14.3,32.6,33.5,39.6$ and $49.8^{\circ}$ ), $\gamma-\mathrm{Al}_{2} \mathrm{O}_{3}$ (with broad, ill-defined peaks at $2 \theta=37.4$,
45.7 and $67.2^{\circ}$ ) and $\alpha-\mathrm{Al}_{2} \mathrm{O}_{3}$ (with well defined peaks at $2 \theta=25.5,35.1,37.6,43.3,52.6,57.4$ and $68.3^{\circ}$ ). $\mathrm{MoS}_{2}$ and $\gamma-\mathrm{Al}_{2} \mathrm{O}_{3}$ were the only species found to be present after reaction with conventional heating, while significant amounts of $\alpha-\mathrm{Al}_{2} \mathrm{O}_{3}$ were observed after reaction under microwave conditions for both catalysts examined. The peaks for $\alpha$-alumina were quite sharp, showing a high degree of crystallinity. Since the phase change from $\gamma$-alumina to $\alpha$-alumina is known to occur at temperatures above $1273 \mathrm{~K}$ [16], and the maximum average temperature recorded in the microwave experiments was $1073 \mathrm{~K}$, it is concluded that microwave heating caused some regions of the catalyst to reach temperatures at least $200^{\circ}$ greater than the average temperatures measured by the optical probe.

Molybdenum sulfide has a layer structure and is known to form slabs which tend to be anchored to the alumina particles via their edge planes $[17,18]$. A reasonable value for the thickness of these molybdenum sulfide slabs can be obtained by applying the Debye-Scherrer line-broadening equation to the XRD peak occurring at $2 \theta=14.3^{\circ}$ [19]. This peak represents the $(002)$ reflection and the line broadening gives the coherence length of the crystallites along the $c$-axis, $L_{\mathrm{c}}$. The latter has been calculated from the equation

$L_{\mathrm{c}}=\frac{0.9 \lambda}{\beta \cos 7.15}$

where $\lambda$ is the wavelength of the X-rays and $\beta$ the width of the peak at half-maximum in radians. The average number of layers of $\mathrm{MoS}_{2}$ in a slab can then be calculated by dividing $L_{\mathrm{c}}$ by $0.619 \mathrm{~nm}$, the thickness of a single layer. The results of this calculation are given in Table 2, where it can be seen that the thickest slabs were found with the mechanically mixed catalyst, for

Table 2

Average number of layers of $\mathrm{MoS}_{2}$ in slab calculated from $\left(\begin{array}{lll}0 & 0 & 2\end{array}\right)$ XRD line broadening

\begin{tabular}{llll}
\hline $\begin{array}{l}\text { Catalyst } \\
\text { sample }\end{array}$ & $\begin{array}{l}\text { Method of } \\
\text { heating }\end{array}$ & $\begin{array}{l}\text { Width of (0 02) peak } \\
\text { at half-maximum }\left({ }^{\circ}\right)\end{array}$ & $\begin{array}{l}\text { Number of } \\
\mathrm{MoS}_{2} \text { layers }\end{array}$ \\
\hline MC-2 & CH & 0.50 & 26 \\
MC-2 & MW & 0.40 & 32 \\
SC-CH & CH & 0.90 & 14 \\
SC-CH & MW & 0.65 & 20 \\
\hline
\end{tabular}


which well-developed $\mathrm{MoS}_{2}$ crystals already existed in the starting material. It is also noticeable that, for a given catalyst, the average thickness of the slabs is greater after microwave heating than after conventional heating, showing that more crystal growth had occurred.

For $\mathrm{MoS}_{2}$ powders it has been found that the width at half-maximum of the $\left(\begin{array}{ll}0 & 0\end{array}\right)$ XRD peak decreases with increasing annealing temperature from about $1.8^{\circ}$ at $450^{\circ} \mathrm{C}$ to about $0.55^{\circ}$ at $900^{\circ} \mathrm{C}$ [20]. On this basis the maximum temperature reached during microwave heating of the MC-2 catalyst must have been considerably in excess of $900^{\circ} \mathrm{C}$, a conclusion which is in keeping with the observed formation of $\alpha$-alumina.

\subsubsection{Scanning electron microscopy examination}

Scanning electron micrographs were taken of catalysts MC-2 and SC-CH, both before and after reaction. It was found that conventional heating in the furnace during reaction did not cause any significant change in the appearance of the surface or the state of dispersion of the $\mathrm{MoS}_{2}$ particles for both catalysts investigated. However, after microwave heating some of the molybdenum disulfide, which was initially evenly distributed as $152-178 \mu \mathrm{m}$ amorphous particles, formed hexagonal crystals. The results for the mechanically mixed catalyst MC-2, are shown in Fig. 1(a). For the supported catalyst the effect of microwave heating was even more marked with extensive formation of hexagonal crystals of $\mathrm{MoS}_{2}$ being observed all over the catalyst, as shown in Fig. 1(b).

Compared with the state of dispersion of the $\mathrm{MoS}_{2}$ before reaction it was notable that a considerable migration of $\mathrm{MoS}_{2}$ had occurred. The melting point of $\mathrm{MoS}_{2}$ is $1458 \mathrm{~K}$, which is some $385^{\circ}$ higher than the maximum average temperature recorded in the microwave experiments. This temperature difference is significantly larger than that required to explain the formation of $\alpha$-alumina. However, complete melting may not be necessary to explain the formation of the hexagonal platelets, since this could equally well come about by a rapid rate of migration of $\mathrm{MoS}_{2}$ moieties across the surface.

The extent of the migration occurring during microwave heating was also demonstrated by the formation of spheres of loosely coagulated material with diameters as large as $2 \mathrm{~mm}$. These spheres were found to contain both $\mathrm{Al}_{2} \mathrm{O}_{3}$ and $\mathrm{MoS}_{2}$.
In summary, X-ray diffraction, scanning electron microscopy and surface area measurements have shown that marked changes occurred in both the $\mathrm{MoS}_{2}$ and $\gamma-\mathrm{Al}_{2} \mathrm{O}_{3}$ components of the catalysts during microwave heating. This is attributed to the formation of hot-spots, which reach a much higher temperature than that measured for the catalyst bed as a whole. This, in turn, resulted in a considerable acceleration in the reaction rate, as described below.

\subsection{Conversion of $\mathrm{SO}_{2}$ and $\mathrm{CH}_{4}$ as a function of temperature with different heating methods}

Fig. 2 compares the $\mathrm{SO}_{2}$ and $\mathrm{CH}_{4}$ conversion efficiencies for catalyst MC-2 as a function of temperature for conventional and microwave dielectric heating at an $\mathrm{SO}_{2} / \mathrm{CH}_{4}$ molar feed ratio of two. It can be seen that significant conversion of $\mathrm{SO}_{2}$ and $\mathrm{CH}_{4}$ to products does not occur with conventional heating until the temperature reaches $600^{\circ} \mathrm{C}$, whereas this can be achieved with microwave heating at temperatures as low as $450^{\circ} \mathrm{C}$. For conversions between 10 and $70 \%$, it is found that the same percentage conversion of $\mathrm{SO}_{2}$ or $\mathrm{CH}_{4}$ can be achieved with microwave heating at temperatures which are about $200^{\circ} \mathrm{C}$ lower than those required when conventional heating was used. This temperature difference is almost exactly the same as that required to explain the formation of $\alpha$-alumina under microwave heating, although, it would be insufficient to cause melting of the $\mathrm{MoS}_{2}$ crystallites. There is, therefore, clear evidence from a number of sources that some regions of the catalyst reach temperatures which are approximately $200^{\circ} \mathrm{C}$ in excess of the measured temperature.

This conclusion is in keeping with that of a previous study of the catalytic decomposition of $\mathrm{H}_{2} \mathrm{~S}$ over $\mathrm{MoS}_{2}$ catalysts [14], where microwave heating caused an acceleration in reaction rates and an apparent shift in the position of equilibrium. As in the current study, the results could be explained only by the formation of hot-spots, which were estimated to have temperatures $100-200^{\circ} \mathrm{C}$ higher than the average bulk temperature measured in the catalyst bed.

With conventional heating the percentage conversion was observed to increase approximately exponentially with temperature throughout the temperature range used. Fig. 3 shows an Arrhenius plot of the data, from which an activation energy of $117 \mathrm{~kJ} \mathrm{~mol}^{-1}$ was 


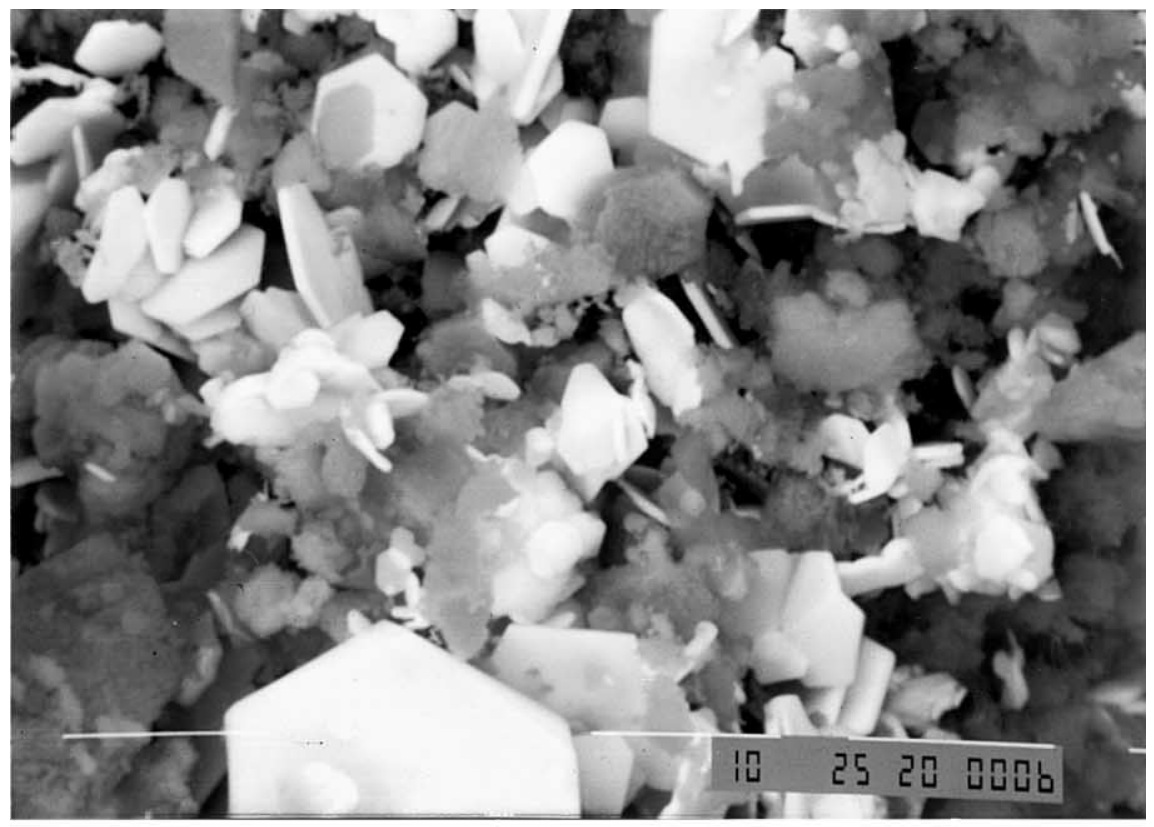

(a)

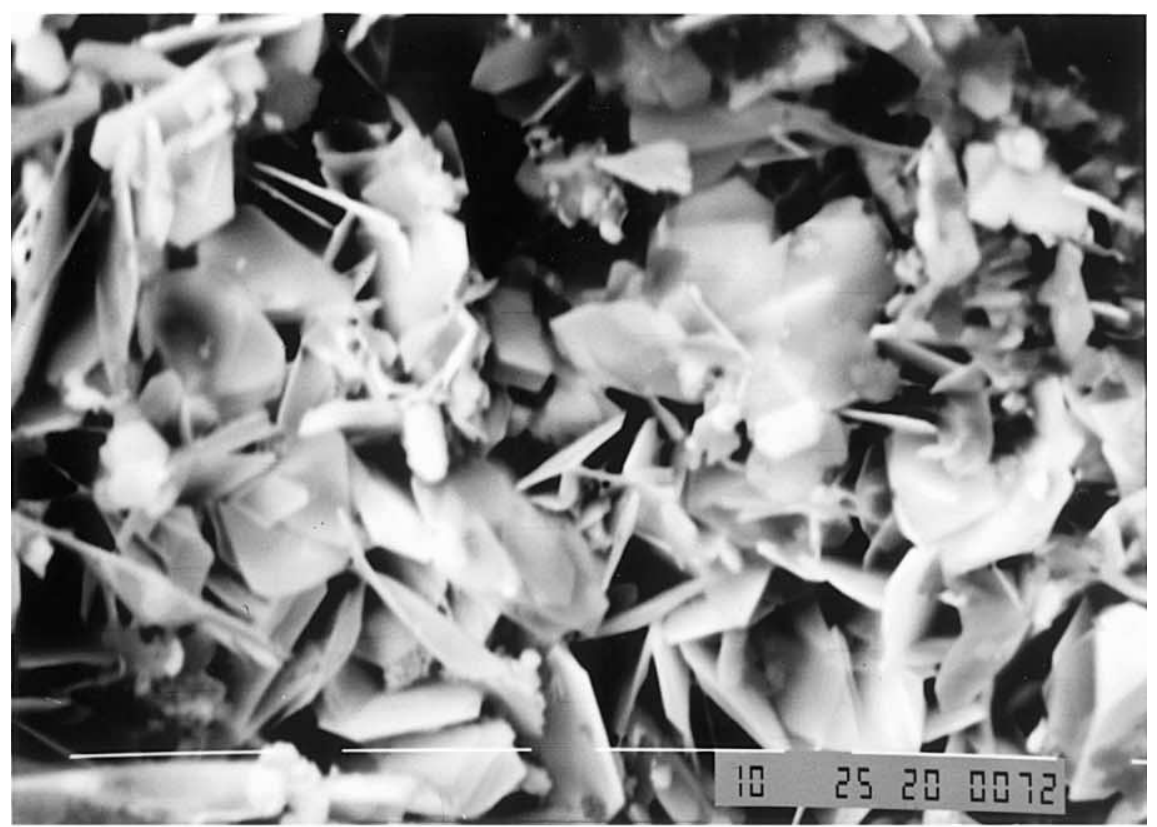

(b)

Fig. 1. Scanning electron micrographs of catalysts after reaction under microwave conditions up to $800^{\circ} \mathrm{C}$. 


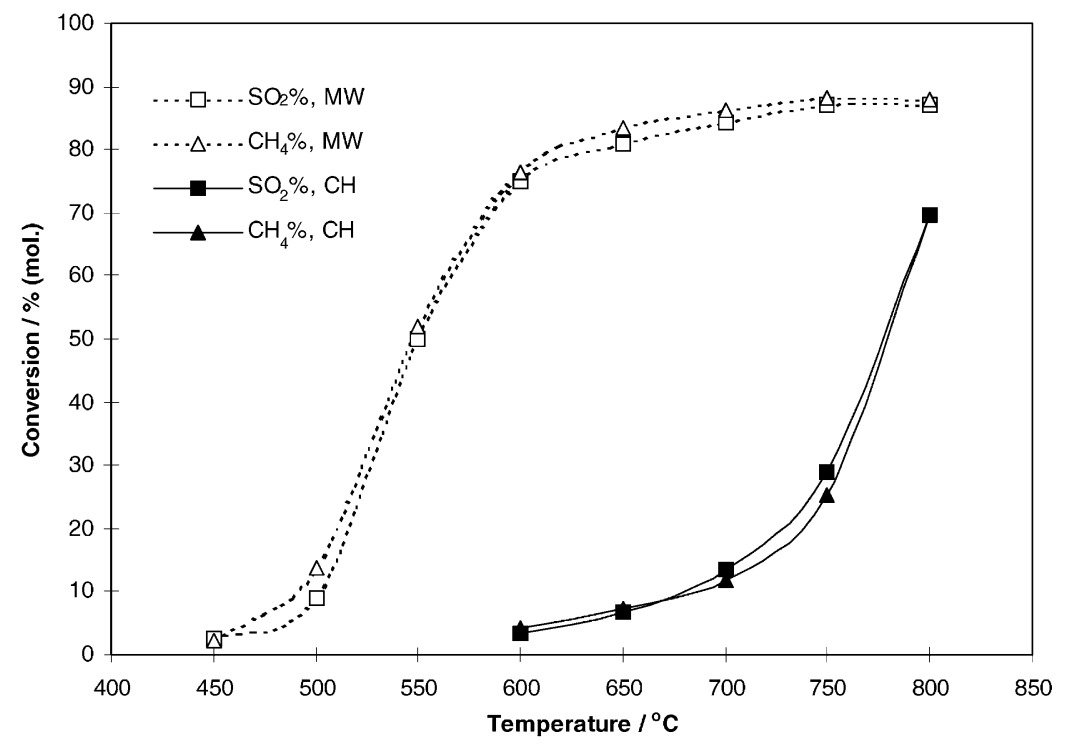

Fig. 2. $\mathrm{SO}_{2}$ and $\mathrm{CH}_{4}$ conversions as a function of temperature over catalyst MC-2.

calculated. It is surprising that the data gives such a good fit to a straight line for temperatures as high as $800^{\circ} \mathrm{C}$ because extrapolation of the straight line would result in $100 \%$ conversion at the slightly higher temperature of $894^{\circ} \mathrm{C}$, a point at which the linear relationship obviously breaks down. Clearly, there must be a sharp change in the rate determining step at temperatures between 800 and $894^{\circ} \mathrm{C}$. The most likely explanation for this behavior is that a surface reaction, or desorption process, is the rate determining step at the

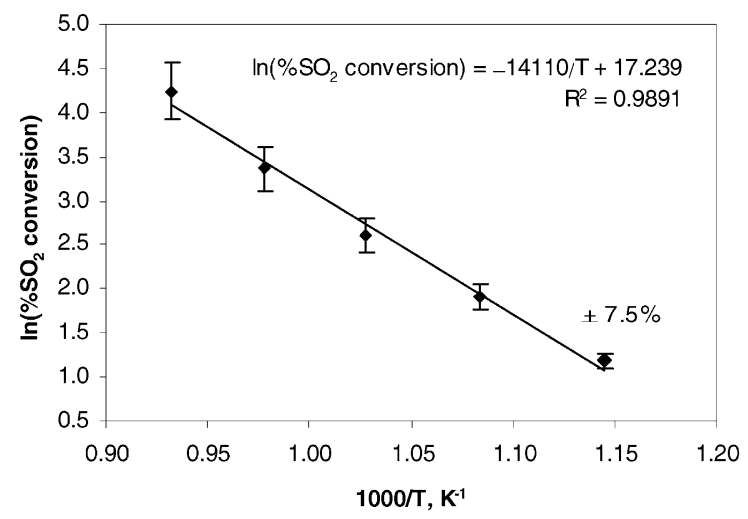

Fig. 3. Plot of $\ln \left(\% \mathrm{SO}_{2}\right.$ conversion $)$ against reciprocal absolute temperature for catalyst $\mathrm{MC}-2$. lower temperatures, but as the temperature is raised the concentration of reactants falls to a critical level below which adsorption takes over as the rate determining step. The measured activation energy would, therefore, refer to a surface or desorption process, one possible reaction being the decomposition of $\mathrm{MoS}_{2}$ to give $\mathrm{S}_{2}(\mathrm{~g})$.

The variation of percentage $\mathrm{SO}_{2}$ conversion with temperature was found to be quite different for the microwave heated catalyst, where there was a rapid rise in percentage conversion to a value of $50 \%$ at a temperature of $550^{\circ} \mathrm{C}$, followed by a much more gradual rise to a maximum value of $90 \%$ at temperatures greater than $750^{\circ} \mathrm{C}$. This difference can be accounted for by the non-uniformity of the temperature in the microwave heated catalyst. The rapid rise in the percentage $\mathrm{SO}_{2}$ conversion, observed at temperatures approximately $200^{\circ}$ below those observed with conventional heating, is believed to be caused by reactions occurring at the hot spots. These hot spots tend to be concentrated at the center of the catalyst and the more peripheral parts of the catalyst are cooler. As the temperature is raised $\mathrm{SO}_{2}$ passing over these more peripheral parts begins to react and this could give rise to the shape of the curve shown in Fig. 2.

The reason why the percentage $\mathrm{SO}_{2}$ conversion tends to level off at high temperatures at $90 \%$, rather 
than $100 \%$, is not clear. It cannot be caused by an approach to equilibrium because the free energy of reaction (6) is calculated to be $-225 \mathrm{~kJ} \mathrm{~mol}^{-1}$ at $1000 \mathrm{~K}$, a value which is sufficiently negative to make the concentrations of reactants present at equilibrium entirely negligible. The most likely explanation is that the maximum conversion of $90 \%$ is determined by the efficiency of the catalyst bed, which may allow a small percentage of reactant molecules to pass through it without coming into contact with the active sites in the catalyst surface.

Finally, it should be noted that the percentage conversion of $\mathrm{SO}_{2}$ is found to be equal to the percentage conversion of $\mathrm{CH}_{4}$ at all temperatures, irrespective of the method of heating. Since the gas mixture contains twice as much $\mathrm{SO}_{2}$ as $\mathrm{CH}_{4}$ this result shows that two molecules of $\mathrm{SO}_{2}$ react with each molecule of $\mathrm{CH}_{4}$, in accordance with Eq. (6).

\subsection{Comparison of catalyst activity}

The percent conversions of $\mathrm{SO}_{2}$ and $\mathrm{CH}_{4}$ obtained over a wide range of temperatures with four different catalysts are compared in Fig. 4 for both conventional and microwave heating.

With conventional heating the activities of the catalysts are generally in the order

$$
(\mathrm{SC}-\mathrm{CH})>(\mathrm{SC}-\mathrm{MW})>(\mathrm{MC}-2)>(\mathrm{MC}-1)
$$

with catalyst MC-1 having a markedly lower activity than the other catalysts. This order cannot be rationalized in terms of total surface areas because Table 1 shows that catalyst MC-1 has the highest surface area after reaction with conventional heating whilst the other three catalysts all have approximately the same area. The main difference between catalyst MC-1 and the others is that it contains relatively large alumina and $\mathrm{MoS}_{2}$ particles whereas there is intimate mixing of the two components in the other catalysts. Thus, catalysts SC-CH and SC-MW have both been prepared by the impregnation technique whilst catalyst MC-2 has been prepared by compressing a mixture of fine $\mathrm{MoS}_{2}$ and alumina powders into pellets followed by grinding and sieving. The low activity of the MC-1 catalyst, is therefore, likely to be associated with the low area of contact between the alumina and $\mathrm{MoS}_{2}$ particles, which may indicate that reaction occurs preferentially at the alumina- $\mathrm{MoS}_{2}$ interface.
The order of activity of the catalysts under microwave heating is as follows:

$(\mathrm{MC}-2)>(\mathrm{SC}-\mathrm{CH})>(\mathrm{SC}-\mathrm{MW})>(\mathrm{MC}-1)$

The most significant feature is that the mechanically mixed catalyst MC-2 is now found to be the most active. This could arise either because parts of the catalyst bed have been heated to higher temperatures than those attained with the other catalysts or because the MC-2 catalyst has a higher basic activity.

Finally, it was observed that the supported catalysts sulfided prior to reaction, either under microwave conditions or by conventional heating, showed no significant difference in $\mathrm{SO}_{2}$ conversion efficiency. This result indicated that the microwave radiation had no significant effects on the sulfidation process.

\subsection{Effects of feed gas composition on $\mathrm{SO}_{2}$ conversion and product selectivity}

The effect of changing the molar $\mathrm{SO}_{2} / \mathrm{CH}_{4}$ ratio on the conversion of $\mathrm{SO}_{2}$ is shown in Fig. 5 for microwave heating at different temperature levels over catalyst $\mathrm{MC}-2$. It can be seen that a very high conversion rate is maintained for $\mathrm{SO}_{2} / \mathrm{CH}_{4}$ molar ratios between 1 and 2, but that the conversion efficiency drops off markedly when the $\mathrm{SO}_{2}$ is in excess of the stoichiometric ratio required for reaction (6).

Fig. 6 illustrates the effects of the feed gas composition on the product selectivity at a temperature of $650^{\circ} \mathrm{C}$ over catalyst MC-2 under microwave conditions. It is apparent that as the $\mathrm{SO}_{2} / \mathrm{CH}_{4}$ molar ratio is reduced from 2 to 1 the yields of sulfur and $\mathrm{CO}_{2}$ fall whilst the yields of less desirable by-products increase significantly. This is because the excess methane reacts with sulfur to produce $\mathrm{CO}$ and $\mathrm{H}_{2} \mathrm{~S}$. It is also undesirable to operate with an excess of $\mathrm{SO}_{2}$ because the overall conversion of $\mathrm{SO}_{2}$ drops significantly to reach a value of about $55 \%$ at a molar $\mathrm{SO}_{2} / \mathrm{CH}_{4}$ ratio of 3 . It is clear that the best results were obtained when the molar ratio for $\mathrm{SO}_{2} / \mathrm{CH}_{4}$ was close to the stoichiometric value of 2 .

\subsection{Catalyst stability under microwave heating}

For microwave heating at recorded temperatures up to $700^{\circ} \mathrm{C}$, the catalysts appeared to be quite stable and 

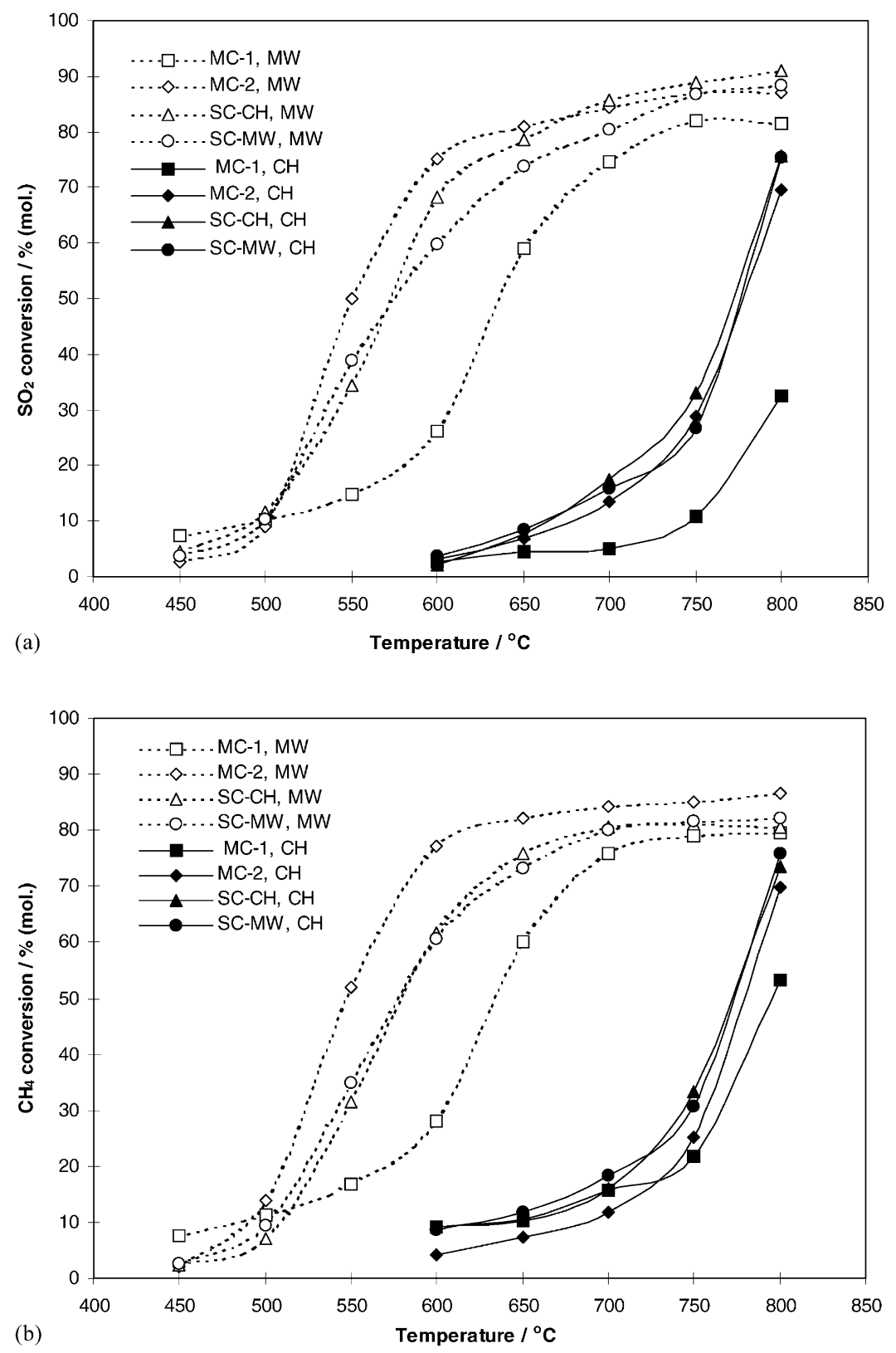

Fig. 4. Comparison of $\mathrm{SO}_{2}$ and $\mathrm{CH}_{4}$ conversions as a function of temperature for a variety of catalysts.

it was possible to obtain reproducible results, when the temperature was raised and lowered over a period of about $2 \mathrm{~h}$. For recorded temperatures above $700^{\circ} \mathrm{C}$ a slow decline in activity was observed and it may be significant that this is the temperature range in which the formation of $\alpha$-alumina and the growth of large, hexagonal $\mathrm{MoS}_{2}$ crystallites was first observed. There is much evidence to show that the catalytic activity of the $\mathrm{MoS}_{2}$ platelets resides at the edges, where the molybdenum atoms are exposed [18]. This being so, 


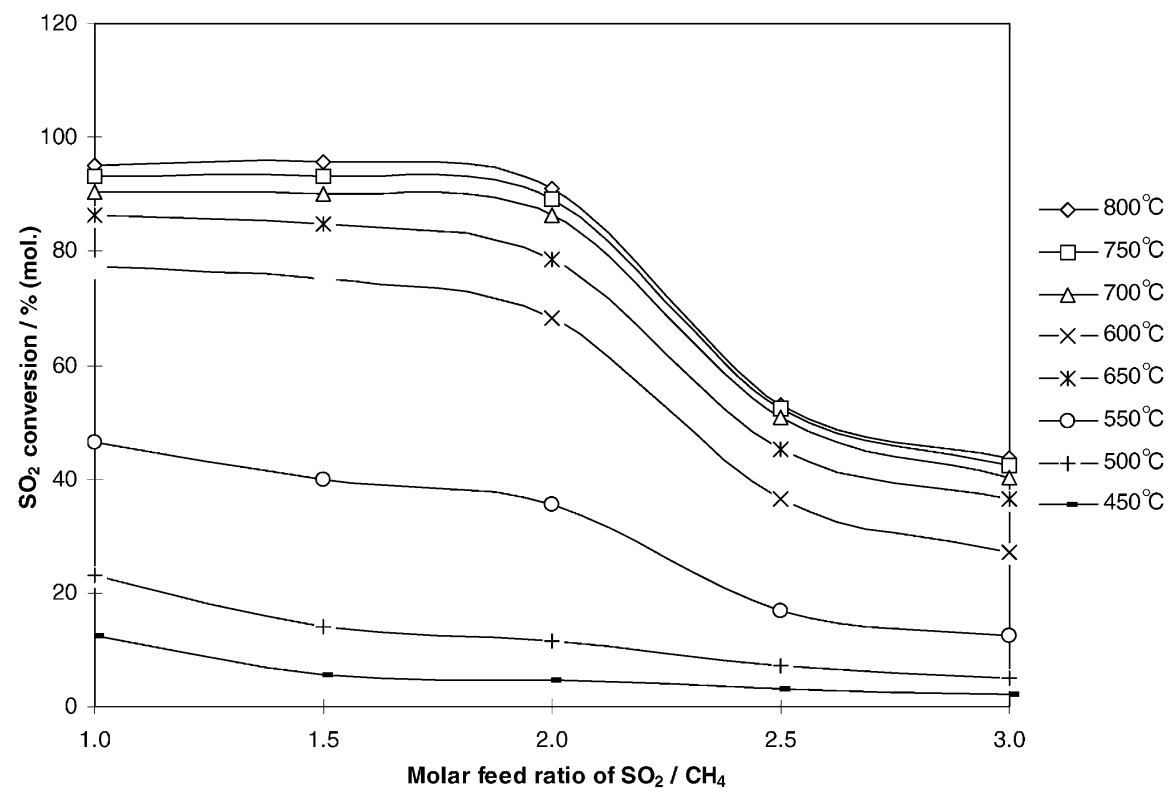

Fig. 5. Effects of the feed gas composition on $\mathrm{SO}_{2}$ conversion for catalyst MC-2.

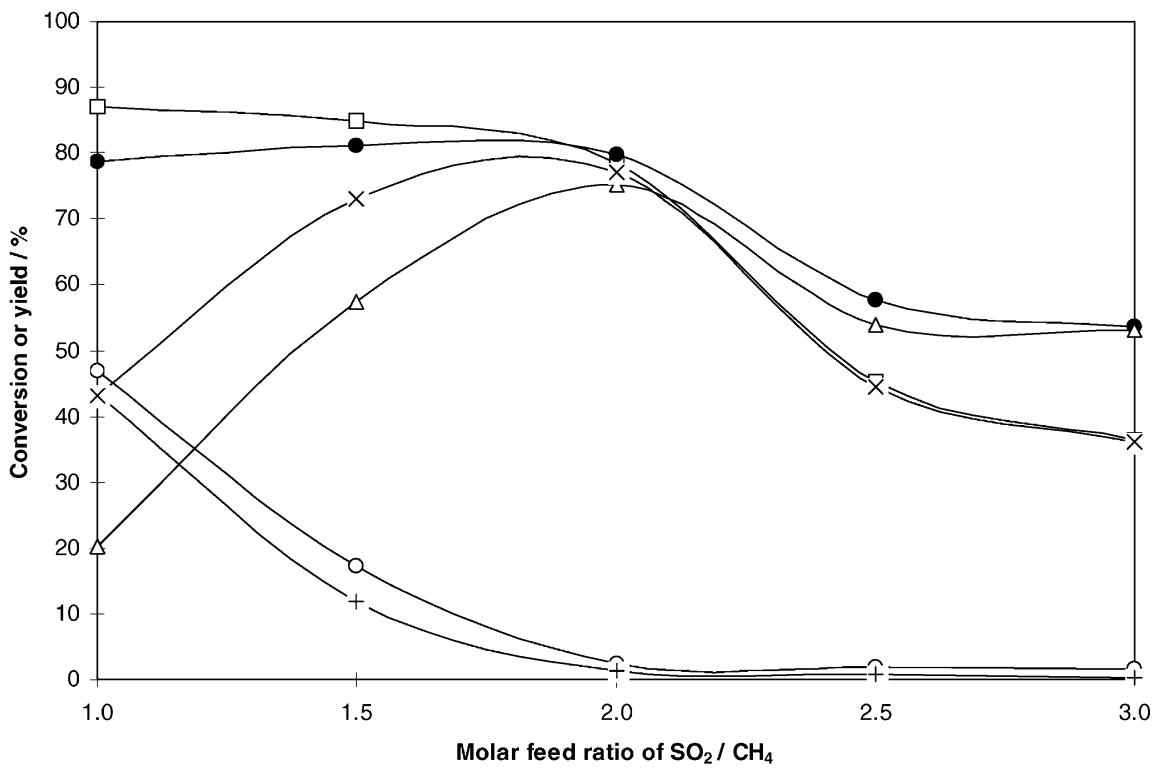

Fig. 6. Effects of the feed gas composition on product selectivity for catalyst MC-2. 


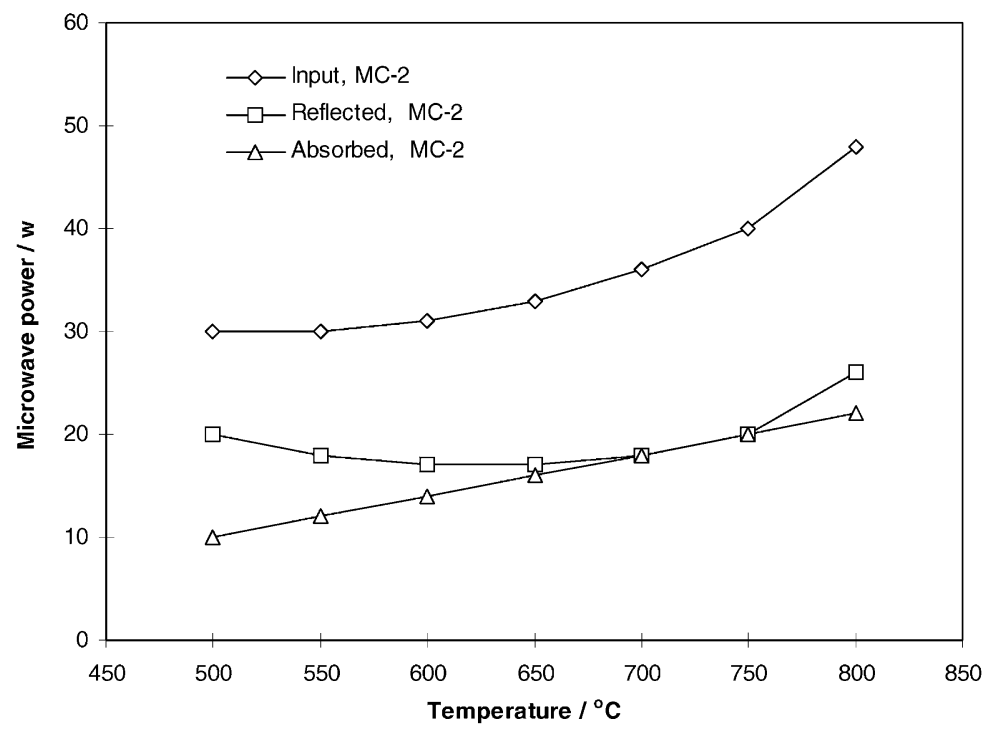

Fig. 7. Microwave power vs. temperature for catalyst MC-2.

activity would be expected to drop as the dimensions of the platelets increase.

\subsection{Microwave power as a function of the temperature of catalyst bed}

The cavity used for microwave heating was always tuned to minimize the amount of reflected power. Assuming that the system was relatively free of leakage, the power absorbed by the catalyst bed can be calculated as the difference between the output and reflected power.

$$
\begin{aligned}
\text { Absorbed power }(\mathrm{W})= & \text { input power }(\mathrm{W}) \\
& -\operatorname{reflected} \operatorname{power}(\mathrm{W}) .
\end{aligned}
$$

Fig. 7 shows the variation of forward, reflected and absorbed microwave power with the temperature recorded by the probe for catalyst MC- 2 . The fraction of the input power that was reflected dropped from 0.66 at $500^{\circ} \mathrm{C}$ to about 0.50 at $650^{\circ} \mathrm{C}$, after which it remained approximately constant. For this reason, only a slight increase in the input power was needed to raise the temperature from 500 to $650^{\circ} \mathrm{C}$. These results would seem to indicate that the effective dielectric loss factor of the catalyst was increasing at temperatures below $650^{\circ} \mathrm{C}$, but remained fairly constant at higher temperatures.

In work with an $8 \% \mathrm{MoS}_{2}$ /alumina catalyst [21], it was found that the fraction of the input power that was absorbed by the catalyst increased from 0.13 at $18^{\circ} \mathrm{C}$ to 0.25 at $350^{\circ} \mathrm{C}$. The higher values reported here must be due to the greater loading of molybdenum sulfide $(30 \%)$. This material has an effective dielectric loss factor of 0.85 at $200^{\circ} \mathrm{C}$ [22], compared to 0.025 for alumina, and must be responsible for the major part of the heating. The effective dielectric loss factor of the catalyst would be expected to continue rising at temperatures above $650^{\circ} \mathrm{C}$ and the fact that it remains approximately constant may be connected with the formation of $\alpha$-alumina or the growth of the hexagonal platelets of $\mathrm{MoS}_{2}$ seen in Fig. 1.

\section{Conclusions}

The enhanced reaction rates observed with microwave heating seem to result from the formation of hot spots within the catalyst which cause the temperature recorded by the probe to be considerably less than the highest temperature attained in the catalyst. Support for this conclusion comes from the detection of $\alpha$-alumina in catalysts which have been heated to a 
nominal temperature of only $800^{\circ} \mathrm{C}$, using microwave heating. The difference in temperature between the hot spots and the remainder of the catalyst is dependent upon the overall composition of the catalyst and the degree of contact between the $\mathrm{MoS}_{2}$ and $\mathrm{Al}_{2} \mathrm{O}_{3}$ components. No significant differences could be detected between catalysts which had been heated by microwaves during sulfiding and those where conventional heating had been used.

\section{References}

[1] H.M. Apsimon, R.F. Warren, J.J.N. Wilson, Atmos. Environ. 28 (1994) 649.

[2] B. Lees, Chem. Br. 25 (1989) 38.

[3] W.Z. Khan, B.M. Gibbs, Environ. Int. 23 (1997) 227.

[4] W.Z. Khan, B.M. Gibbs, Fuel 74 (1995) 800.

[5] M.J. Munoz-Guillena, A. Linares-Solano, C. Salinas-Martinez de Lecea, Appl. Surf. Sci. 81 (1994) 409.

[6] K. Kuuspalo, T. Alander, T. Raunemaa, M. Noponen, J. Aerosol Sci. 22 (1991) S471.

[7] V.E. Kaloidas, N.G. Papayannakos, Int. J. Hydrogen Energy 12 (1987) 403
[8] J. Sarlis, D. Berk, Ind. Eng. Chem. Res. 27 (1988) 1951.

[9] J.J. Yu, Q. Yu, Y. Jin, S.G. Chang, Ind. Eng. Chem. Res. 36 (1997) 2128.

[10] D.J. Mulligan, K. Tam, D. Berk, Can. J. Chem. Eng. 73 (1995) 351.

[11] D.J. Mulligan, D. Berk, Ind. Eng. Chem. Res. 31 (1992) 119.

[12] D.J. Mulligan, D. Berk, Ind. Eng. Chem. Res. 28 (1989) 926.

[13] F. Chemat, D.C. Esveld, M. Poux, J.L. Di-Martino, J. Microwave Power Electromagn. Energy 33 (1998) 88.

[14] X.L. Zhang, D.O. Hayward, D.M.P. Mingos, Chem. Commun. (1999) 975.

[15] S. Ringler, P. Girard, G. Maire, S. Hilaire, G. Roussy, F. Garin, Appl. Catal. B 20 (1999) 219.

[16] Powder Diffraction Files, Inorganic Vol. PD1S-10iRB, Joint Committee on Powder Diffraction Standards, Philadephia, 1967.

[17] T.F. Hayden, J.A. Dumesic, J. Catal. 103 (1987) 366.

[18] R.R. Chianelli, M. Daage, M.J. Ledoux, Adv. Catal. 40 (1994) 177.

[19] S.S. Pollack, L.E. Makovsky, F.R. Brown, J. Catal. 59 (1979) 452.

[20] C.R. Roxlo, M. Daage, A.F. Ruppert, R.R. Chianelli, J. Catal. 100 (1986) 176.

[21] X.L. Zhang, D.O. Hayward, D.M.P. Mingos, Ind. Eng. Chem. Res. (in press).

[22] X.L. Zhang, Ph.D. Thesis, University of London, 2000. 